Cahiers $d u$ MONDE RUSSE

\section{Cahiers du monde russe}

Russie - Empire russe - Union soviétique et États indépendants

$44 / 4 \mid 2003$

Varia

\title{
Boris-Mathieu Petric, Pouvoir, don et réseaux en Ouzbékistan post-soviétique
}

\section{Marlène Laruelle}

\section{OpenEdition \\ Journals}

Édition électronique

URL : https://journals.openedition.org/monderusse/4140

DOI : 10.4000/monderusse.4140

ISSN : $1777-5388$

Éditeur

Éditions de l'EHESS

\section{Édition imprimée}

Date de publication : 1 octobre 2003

Pagination : 799-800

ISBN : 2-7132-1833-0

ISSN : $1252-6576$

Référence électronique

Marlène Laruelle, "Boris-Mathieu Petric, Pouvoir, don et réseaux en Ouzbékistan post-soviétique », Cahiers du monde russe [En ligne], 44/4 | 2003, mis en ligne le 19 juin 2009, consulté le 03 septembre 2022. URL : http://journals.openedition.org/monderusse/4140 ; DOI : https://doi.org/10.4000/ monderusse. 4140

Ce document a été généré automatiquement le 3 septembre 2022.

Tous droits réservés 


\title{
Boris-Mathieu Petric, Pouvoir, don et réseaux en Ouzbékistan post- soviétique
}

\author{
Marlène Laruelle
}

\section{RÉFÉRENCE}

Boris-Mathieu PETRIC, Pouvoir, don et réseaux en Ouzbékistan post-soviétique.

Paris, PUF, 2002, 297 p. (Partage du savoir)

1 Le livre de Boris-Mathieu Petric propose une approche anthropologique générale de l'Ouzbékistan post-soviétique, qui manquait jusqu'ici. Celle-ci permet de mieux analyser une société centrasiatique très peu connue du public occidental, tout particulièrement francophone, et propose un regard spécifique sur l'une des expériences possibles de sortie du système soviétique.

2 Après une présentation historique, l'auteur s'intéresse aux questions de parenté, de lignage et de filiation. Celles-ci dessinent une société ouzbèke complexe, dans laquelle les enjeux identitaires sont multiples et enchevêtrés: prescriptions matrimoniales, importance de l'origine spatiale dans la constitution d'une identité locale, réseaux régionaux et familiaux de solidarité, construction problématique d'une nationalité ouzbèke, place marginale des minorités, qu'elles soient "européennes» (Russes, Arméniens) ou présentes depuis longtemps sur un sol entre-temps devenu ouzbek (Tadjiks, Ironis, Arabes, Karakalpaks, etc.).

Une place importante de l'ouvrage est accordée au fonctionnement de la mahalla, cette organisation sociale et territoriale du « quartier », ainsi qu'aux échanges sociaux, et tout particulièrement au système de dons et contre-dons. Ceux-ci formalisent une grande part des rapports sociaux en instituant toute une série d'obligations entre les protagonistes, puisque la réciprocité du don ne signifie en aucun cas l'égalité. L'auteur y exploite un matériel rare et difficile à obtenir - les cahiers de dons tenus par les familles - qui aide à 
prendre conscience de l'importance matérielle des transactions de biens ou d'argent dans une société où il est impossible de transmettre une position sociale par héritage: les grands rites de passage ou les fêtes traditionnelles permettent la circulation, la concentration et la redistribution des richesses dans un système en apparence rigide mais où tout, en réalité, se négocie.

4 La quatrième partie se révèle particulièrement intéressante pour tous ceux qui s'intéressent à la gestion du pouvoir dans le monde post-soviétique: le système clientéliste ouzbek est en effet autant le produit de rapports traditionnels de fidélité par réseaux que la poursuite du mode de fonctionnement développé à l'époque soviétique. Plus encore que dans les années 1970, les réseaux politiques et économiques sont profondément entremêlés et contribuent à la "nationalisation de la mafia». Les structures étatiques et les institutions de formation des élites (comme l'Académie de construction de l'État et de la société, où a travaillé l'auteur) sont devenues un lieu de combat pour les factions et les réseaux, tout comme l'ensemble des postes administratifs régionaux ou locaux. Malgré cette absence de distinction entre mandats politique et administratif, il existe dans l'Ouzbékistan contemporain une certaine fluidité du pouvoir, régulé par un subtil jeu de nominations-révocations décidé à la tête de l'État.

On regrettera cependant que la partie historique s'étende autant sur la période prérévolutionnaire et souligne trop, à notre avis, une prétendue différenciation entre population sédentaire iranophone et population turcique nomade qui recouperait celle entre pouvoir religieux et pouvoir politique. Il aurait probablement été préférable d'insister davantage sur l'expérience soviétique, fondatrice pour la formulation des questions nationales, mais également pour la constitution des systèmes de réseaux clientélistes tels que l'Ouzbékistan d'aujourd'hui les connaît. On notera également quelques inexactitudes historiques dans la première partie et le glossaire, et des confusions dans la translittération du russe.

6 L'auteur offre toutefois un éclairage jusque-là absent dans les sciences sociales françaises sur la réalité de l'Asie centrale post-soviétique. Il met en lumière des mécanismes de pouvoir qui ne sont ni la contrainte physique, ni l'idée occidentale d'une légitimité par la représentativité : l'espace des pratiques sociales et politiques n'est en rien celui qui est officiellement dédié au débat public dans une société gérée par un pouvoir de plus en plus autoritaire et paternaliste. L'ouvrage contribue à la connaissance des sociétés centrasiatiques en révélant, par une étude de terrain intéressante et des exemples précis, à quel point les réseaux familiaux et régionaux de solidarité sont aujourd'hui les seuls à même de donner une quelconque position sociale. Sa contribution est importante également pour les études soviétiques et post-soviétiques en général en confirmant que l'État n'est pas, dans cet espace, une notion abstraite mais avant tout une réalité constituée de personnes et de pratiques qui façonnent à leur avantage et s'approprient l'institution. 